\title{
ERRATUM
}

\section{Erratum to: Responses of the Leading Mode of Coldwave Intensity in China to a Warming Climate}

MA Tingting (马婷婷), JIANG Zhihong* (江志红), and WU Zhiwei (吴志伟)

Key Laboratory of Meteorological Disaster of Ministry of Education, Nanjing University of Information Science \&

Technology, Nanjing 210044

Citation: Erratum to: Responses of the Leading Mode of Coldwave Intensity in China to a Warming Climate. J. Meteor. Res., 2014: 28(2), 325, doi:10.1007/s13351-014-1016-3

(C)The Chinese Meteorological Society and Springer-Verlag Berlin Heidelberg 2013

Erratum to: Acta Meteor Sinica

DOI 10.1007/s13351-013-0503-1

The original version of this article unfortunately contained a mistake. The presentation of DOI number was incorrect.

The corrected DOI number is 10.1007/s13351-013-0103-1

The online version of the original article can be found at http://dx.doi.org/ 10.1007/s13351-013-0503-1

Supported by the National Basic Research and Development (973) Program of China (2013CB430202 and 2010CB950401), National Natural Science Foundation of China (41230528), China Meteorological Administration Special Public Welfare Research Fund (GYHY200906016), and Priority Academic Program Development (PAPD) of Jiangsu Higher Education Institutions.

*Corresponding author: zhjiang@nuist.edu.cn. 